\title{
COMPARISON BETWEEN CONVENTIONAL BLOOD CULTURE AND LYSIS-CENTRIFUGATION METHOD IN SUSPECTED CASES OF SEPSIS IN CHILDREN IN KATIHAR, BIHAR
}

\author{
Nafisa Rahman'1, Kahkashan Akhter², Aninda Sen³, Sangeeta Dey ${ }^{4}$ \\ 1 Junior Resident, Department of Microbiology, Katihar Medical College, Katihar, Bihar, India. \\ ${ }^{2}$ Assistant Professor, Department of Microbiology, Katihar Medical College, Katihar, Bihar, India. \\ 3Professor, Department of Microbiology, Katihar Medical College, Katihar, Bihar, India. \\ 4Professor, Department of Microbiology, Katihar Medical College, Katihar, Bihar, India.
}

\section{BACKGROUND}

ABSTRACT

Blood cultures are a valuable diagnostic tool and indicate whether there is clinical evidence of sepsis or an unknown systemic infection. There are two types of manual blood culture methods: conventional and lysis-centrifugation. Lysis-centrifugation is more sensitive and requires less time. We wanted to isolate and identify pathogens from blood cultures by lysis-centrifugation and conventional method and also to estimate the recovery and contamination rates by these two methods.

\section{METHODS}

Blood was obtained from children, with suspicion of sepsis. Collection was done in blood culture bottles and in test tubes with saponin and sodium polyanethol sulphonate. Samples were processed and identified as per standard protocol.

\section{RESULTS}

Out of 400 samples 118 (29.3\%) showed growth of various organisms and contamination was seen in 27 (6.75\%). The overall culture positivity by the conventional blood culture method was $118(29.3 \%)$ and $60(15.0 \%)$ by the lysis centrifugation method. The most common organism isolated by the conventional method was Escherichia coli.

\section{CONCLUSIONS}

Lysis centrifugation method did not prove to be as efficient as conventional blood culture. However, contamination rates were lower and the turnaround time for recovery of isolates was lesser by the lysis centrifugation method.

HOW TO CITE THIS ARTICLE: Rahman N, Akhter K, Sen A, et al. Comparison between conventional blood culture and lysiscentrifugation method in suspected cases of sepsis in children in Katihar, Bihar. J. Evolution Med. Dent. Sci. 2019;8(14):1107-1110, DOI: $10.14260 /$ jemds/2019/245

\section{BACKGROUND}

Sepsis is defined as combination of systemic inflammatory response syndrome (SIRS) with suspected or proven bacteraemia/fungemia. SIRS is defined as presence of at least two of the following-

- $\quad$ Temperature $>38^{\circ} \mathrm{C}$ or $<36^{\circ} \mathrm{C}$.

- Respiratory rate $>20 /$ min or $\mathrm{PaCO}_{2}<32$ Torr.

- Heart rate $>90 / \mathrm{min}$.

- Leucocytes $>12000 / \mathrm{dl}$ or $<4000 / \mathrm{dl}$ or $>10 \%$ bands cells.

Invasion of the bloodstream by living microorganism causes significant morbidity and mortality. Hence, blood cultures have become and still remain an essential requisite for diagnosis of sepsis. Blood cultures are a valuable diagnostic tool and indicate whenever there is clinical evidence of sepsis or an unknown systemic infection. Clinical suspicion of any infection that may be associated with bacteraemia or fungemia such as meningitis, cholangitis,

'Financial or Other Competing Interest': None.

Submission 30-01-2019, Peer Review 21-03-2019,

Acceptance 29-03-2019, Published 08-04-2019.

Corresponding Author:

Dr. Sangeeta Dey,

Department of Microbiology,

Katihar Medial College,

Karim Bagh, Katihar-854105,

Bihar, India.

E-mail: sangeetadey@rediffmail.com

DOI: $10.14260 /$ jemds $/ 2019 / 245$

\section{(c) $\odot$ () $\ominus$}

endocarditis and osteomyelitis warrant the cultural examination of the patient's blood. The final identification of a microorganism by the conventional blood culture method takes about 2 to 3 days provided the organism grow in the first subculture done within 6 to $18 \mathrm{hrs}$ after the receipt of the sample. ${ }^{1} \mathrm{~A}$ commercial lysis-centrifugation blood culture system has become available for routine use. The lysis centrifugation method concentrates and separates microorganism from plasma, thereby getting separated from antibiotics and other antibacterial factors that may also be present in blood. This method results in the increased isolation of Staphylococcus aureus, Pseudomonas sp. and yeasts when compared with standard broth blood culture system. $^{2}$ Lysis-centrifugation and lysis-filtration were introduced to increase the sensitivity of methods for detecting microorganisms in the blood. With the lysiscentrifugation system, bacteria were isolated an average of 1 day earlier and yeasts were isolated an average of 2 days earlier. Earlier availability of isolated colonies on agar plates is a distinct advantage of the lysis-centrifugation system especially in cases of polymicrobic septicaemia and enables the inoculum size to be standardized for organism identification and antimicrobial susceptibility testing. ${ }^{2}$
Aims and Objectives
The present hospital based cross-sectional study aimed to determine the diagnostic accuracy of two blood culture methods viz. conventional and lysis-centrifugation methods. The objectives were to isolate and identify bacterial pathogens isolated from blood cultures and also to estimate the recovery rate of bacteria (In cases of sepsis) by lysis- 
centrifugation and conventional method and compare the turnaround time and contamination rates by these two methods.

\section{METHODS}

The present hospital based cross-sectional study was conducted in the Department of Microbiology, Katihar Medical College and Hospital, Katihar from December 2016 to May 2018. Informed consent was obtained from parents of each and every child before collection of samples for the study.

A total of 400 samples were collected from children with suspicion of sepsis. With strict aseptic precaution $4 \mathrm{ml}$ of blood was collected, out of which $2 \mathrm{ml}$ was inoculated into blood culture bottles with $20 \mathrm{ml}$ of trypticase soy broth and another $2 \mathrm{ml}$ in screw capped test tubes with saponin and sodium polyanethol sulphonate (SPS). Blood was collected during the fever spike or just before the next dose of antibiotic.

All blood culture bottles were incubated at $35^{\circ} \mathrm{C}$ examined visually for evidence of growth during the first 12 18 hours after collection. Subculture was done from each bottle after overnight incubation on chocolate agar, blood agar and MacConkey agar plates. ${ }^{3}$

If growth was present, then the isolate was identified up to species level by a battery of biochemical and other tests and antibiotic susceptibility tests were put up. Bottles showing no growth after 48 hours of incubation were again sub-cultured on solid media. If there was no growth after the $2^{\text {nd }}$ subculture a preliminary report was given, and the bottles were incubated for another five days after which a $7^{\text {th }}$ day subculture was done. Those samples showing no growth even after 7 days of incubation ( $3^{\text {rd }}$ subculture) were considered as sterile. 4

Blood samples collected in the screw capped tubes containing saponin and sodium polyanethol sulphonate were centrifuged within two hours of collection at $3000 \mathrm{~g}$ for 30 minutes. Around $0.5 \mathrm{ml}$ of the sediment was spot inoculated on chocolate agar, blood agar and MacConkey agar plates.

The plates were incubated at $35^{\circ} \mathrm{C}$ and plates were examined for any growth after overnight incubation, if no growth then they were further incubated for another 24 hours after which discarded if there was still no growth. ${ }^{5}$ Organisms isolated by this lysis-centrifugation method were also identified to the species level and antibiotic susceptibility tests were put up.

Statistical analysis was carried out using online software. http://www.physics.csbju.deu/stats/contingency_NROW_NC OLUM_form.html P-Value was determined using Chi-square test. $\mathrm{P}$ value $\leq 0.05$ was considered to be significant and $\mathrm{P}$ value $\leq 0.001$ was considered to be highly significant. 6

\section{RESULTS}

Majority of children belonged to the age group $<28$ days $190 / 400(47.5 \%)$ followed by age group $1-5$ years $105 / 400$ (26.25\%) and 5-10 years 59/400 (14.75\%). The overall male to female ratio was $1.4: 1$.

The study showed correlation between blood culture positivity and various risk factors in children. Low birth weight was seen in $73 / 118(61.86 \%)$ of children with positive blood cultures, prematurity in 35/118 (29.66\%) and home delivery in 20/118 (11.04\%). All these findings were found to be statistically significant. [Table 1]

Out of the 400 blood samples collected, 118 (29.3\%) showed growth of various organisms and contamination was seen in 27 (6.75\%). The overall culture positivity by the conventional blood culture method was 118 (29.3\%) and 60 $(15.0 \%)$ by the lysis centrifugation method. Contamination rates were lower $(3.5 \%)$ by lysis centrifugation method as compared to conventional culture method (6.75\%). [Table 2]

The most common organisms isolated by the conventional method was Escherichia coli 35/118 (58.33\%) followed by Pseudomonas aeruginosa 35/118 (18.64\%) and MSSA 17/118 (14.40\%). By the lysis-Centrifugation method, the most common pathogen isolated was Pseudomonas aeruginosa 21/60 (35.00\%) followed by MSSA 09/60 (15.00\%) and Escherichia coli 08/60 (13.33\%).The overall differences in the rate of isolation of organisms by these two methods was found to be statistically highly significant $(\mathrm{P}=$ 0.000) [Table 3]

The commonest contaminants by both the methods were Micrococcus sp. followed by Bacillus sp. The other contaminants encountered were diphtheroids and Staphylococcus epidermidis. Overall the mean time required for growth of all the organisms was much less by the lysiscentrifugation method. [Table 4]

Gram positive cocci showed least resistance to vancomycin and linezolid (100.0\% sensitive) and imipenem to which $79.41 \%$ of strains were sensitive. Maximum resistance was seen with cefuroxime $(61.76 \%)$ followed by cefotaxime and ciprofloxacin $(47.05 \%$ each) and erythromycin and co-trimoxazole ( $41.17 \%$ each). All strains of Pseudomonas aeruginosa were susceptible to netilmicin, tobramycin and colistin (100\%). This was followed by amikacin and imipenem (86.36\% each) and gentamicin and levofloxacin $(77.27 \%$ each). Maximum resistance was seen with cefotaxime (63.63\%) and aztreonam (59.09\%).All GNB were sensitive to colistin $(100 \%)$ followed by imipenem $(74.07 \%)$ and amikacin (72.22\%). Maximum resistance was seen with ampicillin, cefuroxime and aztreonam $(66.66 \%$ each) followed by cefotaxime (53.70\%).

\begin{tabular}{|c|c|c|c|}
\hline Risk Factor & $\begin{array}{c}\text { With +ve } \\
\text { Blood Culture } \\
(\mathbf{n = 1 1 8 ) ( \% )}\end{array}$ & $\begin{array}{c}\text { With -ve } \\
\text { Blood Culture } \\
(\mathbf{n = 2 8 2})(\%)\end{array}$ & p Value \\
\hline $\begin{array}{c}\text { Low Birth Weight } \\
<2 \mathrm{~kg}\end{array}$ & $73(61.86)$ & $102(36.17)$ & 0.000 \\
\hline $\begin{array}{c}\text { Prematurity <36 } \\
\text { Weeks }\end{array}$ & $35(29.66)$ & $47(16.66)$ & 0.003 \\
\hline $\begin{array}{c}\text { Meconium } \\
\text { Aspiration }\end{array}$ & $05(04.23)$ & $07(02.48)$ & 0.348 \\
\hline Home Delivery & $20(11.04)$ & $08(02.83)$ & 0.000 \\
\hline Oligohydramnios & $08(6.77)$ & $14(04.96)$ & 0.468 \\
\hline
\end{tabular}

Table 1. Risk Factors in Children with Positive and Negative Blood Cultures

\begin{tabular}{|c|c|c|c|}
\hline Results & $\begin{array}{c}\text { Conventional } \\
\text { Blood Culture } \\
(\mathbf{n = 4 0 0 )}(\mathbf{\%})\end{array}$ & $\begin{array}{c}\text { Lysis- } \\
\text { Centrifugation } \\
(\mathbf{n = 4 0 0 )}(\mathbf{\%})\end{array}$ & $\begin{array}{c}\mathbf{p} \\
\text { Value }\end{array}$ \\
\hline Growth & $118(29.50)$ & $60(15.00)$ & 0.000 \\
\hline Contamination & $27(06.75)$ & $14(03.50)$ & 0.034 \\
\hline No Growth & $255(63.75)$ & $326(81.50)$ & 0.014 \\
\hline
\end{tabular}

Table 2. Results of Conventional and Lysis-Centrifugation 


\begin{tabular}{|c|c|c|c|}
\hline Organism & \begin{tabular}{|c|} 
Lysis- \\
Centrifugation \\
Method (\%) \\
\end{tabular} & $\begin{array}{c}\text { Conventional } \\
\text { Culture } \\
(\%) \\
\end{array}$ & p Value \\
\hline $\begin{array}{l}\text { Pseudomonas } \\
\text { aeruginosa }\end{array}$ & $21(35.00)$ & $22(18.64)$ & 0.049 \\
\hline MRSA & $06(10.00)$ & $12(10.16)$ & 0.599 \\
\hline MSSA & $09(15.00)$ & $17(14.40)$ & 0.545 \\
\hline Escherichia coli & $08(13.33)$ & $35(58.33)$ & 0.038 \\
\hline $\begin{array}{c}\text { Klebsiella } \\
\text { pneumoniae }\end{array}$ & $06(10.00)$ & $15(12.71)$ & 0.418 \\
\hline $\begin{array}{l}\text { Enterococcus } \\
\text { faecalis }\end{array}$ & 05 (08.33) & 08 (06.77) & 0.470 \\
\hline $\begin{array}{l}\text { Streptococcus } \\
\text { pneumoniae }\end{array}$ & $02(03.33)$ & 05 (04.23) & 0.566 \\
\hline $\begin{array}{l}\text { Acinetobacter } \\
\text { baumannii }\end{array}$ & $02(03.33)$ & $03(100.00)$ & 0.552 \\
\hline $\begin{array}{l}\text { Alcaligenes } \\
\text { faecalis }\end{array}$ & $01(01.66)$ & $01(00.84)$ & 0.564 \\
\hline $\begin{array}{c}\text { Total } \\
(n=400 *)\end{array}$ & $\begin{array}{c}60 \\
(15.00 \% *)\end{array}$ & $\begin{array}{c}118 \\
(29.50 \% *)\end{array}$ & 0.000 \\
\hline \multicolumn{4}{|c|}{ *Percentage calculated horizontally } \\
\hline \multicolumn{4}{|c|}{$\begin{array}{l}\text { Table 3. Organisms Recovered by Lysis Centrifugation } \\
\text { and Conventional Blood Culture }\end{array}$} \\
\hline
\end{tabular}

\begin{tabular}{|c|c|c|}
\hline Organisms & $\begin{array}{c}\text { Lysis- } \\
\text { Centrifugation } \\
\text { (Mean Time in } \\
\text { Hours) }\end{array}$ & $\begin{array}{c}\text { Conventional } \\
\text { Culture } \\
\text { (Mean Time in } \\
\text { Hours ) }\end{array}$ \\
\hline Escherichia coli & 17 & 47 \\
\hline MRSA & 21 & 51 \\
\hline MSSA & 21 & 48 \\
\hline Pseudomonas aeruginosa & 20 & 44 \\
\hline Klebsiella pneumoniae & 21 & 44 \\
\hline Enterococcus faecalis & 22 & 49 \\
\hline $\begin{array}{c}\text { Streptococcus } \\
\text { pneumoniae }\end{array}$ & 22 & 56 \\
\hline Acinetobacter baumannii & 20 & 48 \\
\hline Alcaligenes faecalis & 22 & 72 \\
\hline
\end{tabular}

Table 4. Mean Time Required for the Growth of Organisms by Lysis-Centrifugation and Conventional Blood Culture

\section{DISCUSSION}

In the present study there was predominance of male children, the male to female ratio was $1.4: 1$. Overall it was seen that majority of suspected cases of sepsis were below one year of age, 220 children where below one year of age as compared to 180 children whose ages ranged from 1 to 12 years.

Growth of pathogenic bacteria was seen in 118 (29.5\%) of samples, contamination was seen in 27 (6.8\%) and 255 samples (63.8\%) showed no growth even after 7 days of incubation. Maximum number of microorganisms grew by the conventional culture method $29.5 \%$ whereas by lysiscentrifugation method only $15.0 \%$ of isolates were recovered. Various other authors have reported higher yields by the lysis-centrifugation method. ${ }^{4}$ As far as contamination was concerned the lysis-centrifugation system showed less contamination rates $3.5 \%$ as compared to conventional blood culture method $6.8 \%$. Other authors have reported greater contamination rates using the lysis-centrifugation method. ${ }^{7}$ Parikh et al (2018) however reported lower contamination rates by the lysis-centrifugation system as compared to conventional blood culture method. ${ }^{8}$

Out of a total of 118 bacterial isolates that were recovered, only $15.0 \%$ grew by both the method. As far as conventional blood culture method is concerned Escherichia coli was the commonest isolate followed by Pseudomonas aeruginosa and MSSA. By the lysis-centrifugation method the commonest isolate were Pseudomonas aeruginosa followed by MSSA and Escherichia coli. Similar findings were reported by Parikh et al (2018). ${ }^{8}$ As far as the growth of contaminants was concerned Micrococcus species and Bacillus species accounted for $37.0 \%$ each. Staphylococcus epidermidis and diphtheroids accounted for $14.8 \%$ and $11.1 \%$ of contaminants respectively. The lysis centrifugation system showed less contamination as compared to conventional blood culture system (3.5\% vs $6.8 \%$ ). Other workers have reported contamination rates with Staphylococcus epidermidis to be as high as $66 \% .{ }^{4}$ It is a well-known fact that contamination occurs more frequently in this age group as blood is often collected from an existing intravenous catheter and not by performing a separate venepunture. ${ }^{7}$

On comparing the mean time required for growth of the organisms by both the systems it was found that the mean time required for growth by lysis-centrifugation system was less than half the time required for growth by the conventional blood culture method. Dorn et al (1979) also reported that for almost every organism the mean time to positivity was shortest with the centrifugation method. ${ }^{9}$

As far as antimicrobial susceptibility was concerned Gram positive cocci (MRSA, MSSA and Streptococcus pneumoniae) showed maximum resistance to cefuroxime $61.8 \%$ followed by cefotaxime and ciprofloxacin $47 \%$ each. All strains were however sensitive to vancomycin and linezolid. As far as Enterococcus species was concerned all strains were sensitive to teicoplanin, vancomycin and linezolid. All strains of Pseudomonas aeruginosa were sensitive to netilmicin, tobramycin and colistin. Maximum resistance was seen with cefotaxime $63.3 \%$ and aztreonam 59.1\%. Gram negative bacilli (other than Pseudomonas aeruginosa) showed maximum sensitivity to colistin $100 \%$, followed by imipenem $74.1 \%$ and amikacin $72.2 \%$. Maximum resistance was seen with ampicillin, cefuroxime and aztreonam $66.6 \%$.

Certain risk factor showed statistically significant association with blood culture positivity like low birth weight ( $<2$ kgs.), premature delivery and home delivery. Some authors have reported that approximately $20 \%$ of very low birth weight (VLBW) (weight $<1.5 \mathrm{~kg}$ ) and preterm infants experience serious systemic infection during their hospital stay. Infact sepsis accounts for approximately half of all deaths beyond the $2^{\text {nd }}$ week of life in VLBW.10,11,12

\section{CONCLUSIONS}

The present study was undertaken in a rural setup in Eastern Bihar. Infants and children admitted in the Department of Paediatrics with signs and symptoms consistent with sepsis were inducted into the study.

Majority of children (47.5\%) were male with an overall male to female ratio of 1.4:1. Majority of patients were from the paediatric ward $52.50 \%$ and the rest were from the Neonatal ICU $47.50 \%$. The percentage positivity of blood culture was $29.5 \%$ by the conventional blood culture method and $15.0 \%$ by the lysis-centrifugation method. The most common organisms isolated by the conventional method were Escherichia coli, Pseudomonas aeruginosa and MSSA. By 
the lysis-centrifugation method the most common pathogen isolated was Pseudomonas aeruginosa, MSSA and Escherichia coli. Contamination rates were found to be more by conventional culture as compared to lysis-centrifugation.

The mean time required for growth of all the organisms was much less by the lysis-centrifugation method. This method reduced the turn-around time for growth of bacteria by more than $50 \%$.

Antibiotic susceptibility results showed an increasing trend in resistance to various antimicrobial agents. This is a worldwide phenomenon which is now catching up even in smaller towns like Katihar where the present study was conducted. Various risk factors were found to be associated with sepsis in neonates, infants and children out of which three factors viz. low birth-weight, prematurity and homedelivery were significantly associated with blood culture positivity. It is evident from the present study that the conventional culture of blood samples cannot be done away with. The lysis-centrifugation can only be advocated in very serious cases where the lesser turn-around time may make a difference to the clinical outcome in a particular case especially in setups where automated culture methods are not available.

\section{REFERENCES}

[1] Seifert H, Wisplinghoff $H$. Bloodstream Infection and Endocarditis. In: Borriello SP, Murray RP, Funke G, eds. Topley and Wilson's microbiology and microbial infections. $10^{\text {th }}$ edn. London: Hodder Arnold 2005:509-44.

[2] Kiehn ET, Wong B, Edward FF, et al. Comparative recovery of bacteria and yeasts from lysiscentrifugation and a conventional blood culture system. J Clin Microbiol 1983;18(2):300-4.

[3] Tille MP. Laboratory Methods and strategies for antimicrobial susceptibility testing. In: Bailey \& Scott's diagnostic microbiology. $13^{\text {th }}$ edn. Missouri: Mosby Inc 2014:168-92.
[4] Henry NK, McLimans CA, Wright AJ, et al. Microbiological and clinical evaluation of the isolator lysis-centrifugation blood culture tube. J Clin Microbiol 1983;17(5):864-9.

[5] Procop GW, Church DL, Hall GS, et al. Introduction to Microbiology. In: Koneman's color atlas and textbook of diagnostic microbiology. $7^{\text {th }}$ edn. Philadelphia: Lippincott Williams and Wilkins 2017:66-110.

[6] http://www.physics.csbju.deu/stats/contingency_NR OW_NCOLUM_form.html accessed on 16.09.2018

[7] Hall KK, Lyman JA. Update review of blood culture contamination. Clin Microbiol Rev 2006;19(4):788802.

[8] Parikh HR, De AS, Baveja SM. Comparison of the lysis centrifugation method with the conventional blood culture method in cases of sepsis in a tertiary care hospital. J Lab Physician 2018;4(2):89-93.

[9] Dorn GL, Land GA, Wilson GE. Improved blood culture technique based on centrifugation: clinical evaluation. J Clin Microbiol 1979;9(3):391-96.

[10] Sohn AH, Garrett DO, Sinkowitz-Cochran RL, et al. Prevalence of nosocomial infections in neonatal intensive care unit patients: results from the first national point-prevalence survey. J Pediatr 2001;139(6):821-7.

[11] Stoll BJ, Hansen N, Fanaroff AA, et al. Late onset sepsis in very low birth weight neonates: the experience of the NICHD National Research Network. Pediatrics 2002;110(2 Pt 1):285-91.

[12] Stover BH, Shulman ST, Bratcher DF, et al. Nosocomial infection rates in US children's hospitals' neonatal and pediatric intensive care units. Am J Infect Control 2001;29(3):152-7. 